\title{
A Culture of Extrinsically Motivated Students: Chemistry
}

\author{
Jessica N. Orvis \\ Georgia Southern University \\ jessorv@georgiasouthern.edu \\ Diana Sturges \\ Georgia Southern University \\ P. Dawn Tysinger \\ Georgia Southern University \\ Keenya Riggins \\ Mercer University \\ Shainaz Landge \\ Georgia Southern University
}

Recent research indicates that students are adopting a consumerist approach to education, while data shows that the best academic outcomes are associated with intrinsic motivation. The goal of the study was to explore student academic motivation in an undergraduate Principles of Chemistry I class. The study targeted 432 students enrolled in 9 sections of the class over two semesters at a mid-sized, public four year university. Student academic motivation was measured using the adapted Academic Motivation Scale (AMS). A total of 311 students returned the survey (response rate = $72 \%)$. The results indicated that students enrolled in Chemistry I classes were extrinsically motivated more than intrinsically motivated. The types of extrinsic motivation identified by students were the least autonomous ones, such as external and introjected regulation.

Keywords: self-determination theory, academic motivation scale, chemistry course. 


\section{Introduction}

A significant number of scholarly reports on student motivation comes from the college classroom environment and indicates that student motivation is vital for success at the university level (Astin, 1984; Howey, 1999; Pintrich, 1988a, 1988b; Ryan et al., 1985). Student motivation has been shown to be a determinant of academic performance and achievement (Pintrich, 2004) with motivated students having better class attendance (Moore et al., 2008) and course grades (Wilson and Wilson, 2007), including a higher first-year academic performance (Allen et al. 2007).

Historically, psychologists have viewed motivation as a unitary concept-one that differs in amount rather than type. In contrast, Self Determination Theory (SDT) (Deci and Ryan, 2008) considers motivation to be a differentiated concept that differs in type and exists along an underlying continuum of autonomy (Ryan \& Deci, 2000): amotivation (AM), extrinsic motivation (EM) and intrinsic motivation (IM). The Academic Motivation Scale (AMS; Figure 1) (Vallerand et al., 1992), a well-tested metric for exploring academic motivation within the SDT perspective, further subdivides IM and EM into three subscales each.

With amotivation, the person perceives (1) a lack of contingency between behavior and the attainment of desired outcomes and/or (2) a lack of ability to perform the behavior that is necessary to attain desired outcomes. As a result, the person experiences passivity and an absence of autonomy.

With extrinsic motivation, the person does an activity, because it leads to a separable outcome or consequence, such as obtaining a reward or avoiding a punishment. SDT specifies three types of extrinsic motivation that vary in the degree to which they are internalized into the self and, therefore, autonomous. The least internalized type of extrinsic motivation is external regulation (EM-External Regulation; EM-ER), in which the person is motivated by the salience of external rewards or punishments. The next type of extrinsic motivation is introjected regulation (EM-Introjected Regulation; EM-IN), in which the person is motivated by the salience of internal rewards (e.g., pride) or punishments (e.g., guilt). Both external regulation and introjected regulation are experienced as relatively controlled forms of extrinsic motivation. As the process of internalization proceeds, the next type of extrinsic motivation is identified regulation (EM-Identified Regulation, EM-IN), in which the person is motivated by the value and/or importance of the activity. Identified regulation is the most internalized type of extrinsic motivation in the AMS.

With intrinsic motivation, the person does an activity because it is inherently satisfying and enjoyable. That is, there are no separable outcomes or contingencies that initiate and maintain the behavior; rather, intrinsically motivated behaviors occur spontaneously and are accompanied by experiences of interest, excitement, and enjoyment. Intrinsic motivation (along with well- internalized forms of extrinsic motivation; viz., identified regulation) is the prototype of autonomous, self-determined behavior. The three types of intrinsic motivation are intrinsic motivation to know (IM-To Know; IM-TK), intrinsic motivation toward accomplishments (IM- To Accomplish; IM-TA), and intrinsic motivation to experience stimulation (IM-Stimulation; IM- ST). IM-To Know is seen when an individual engages in a behavior for the satisfaction experienced while learning or trying to understand something new. IM-To Accomplish occurs when an individual engages in a behavior for the pleasure experienced while trying to accomplish a task or create something. IM-Stimulation transpires when an individual engages in a behavior in order to experience stimulating or exciting sensations.

More recently SDT studies have found that there is less distinction between intrinsic and extrinsic types of motivation and more of a sliding scale between behaviors that are more Journal of the Scholarship of Teaching and Learning, Vol. 18, No. 1, January 2018. 
autonomous and intrinsically motivated versus behaviors that are less autonomous and extrinsically motivated (Ryan \& Deci, 2000).

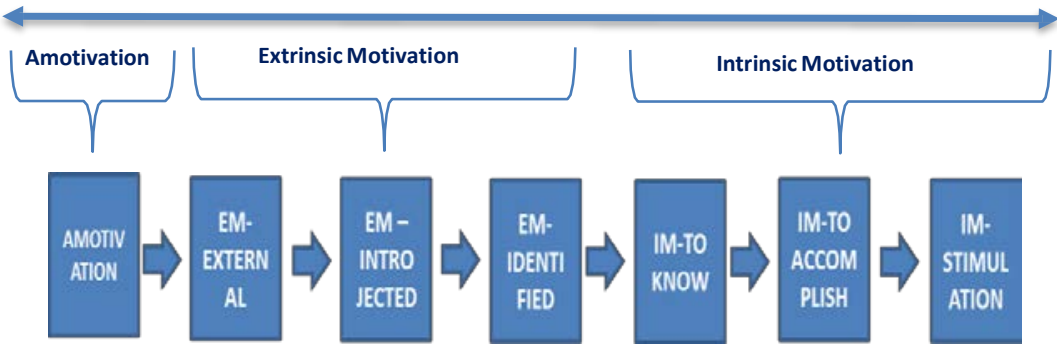

Figure 1: Academic Motivation Scale (AMS)

In the literature, the relationship between motivation type and academic achievement is inconsistent. Some researchers indicated intrinsic motivation is most important to academic success (Deci \& Ryan 2000), while others supported the importance of extrinsic types of motivation (Eliot and Moller, 2004). Both intrinsic and the more autonomous extrinsic types of motivation were linked to positive academic outcomes (Pintrich and De Groot, 1990). IM and EM-Identified Regulation types corresponded positively with GPA, while AM corresponded negatively with GPA (Erten, 2014). Intrinsic motivation was also associated with lower dropout rates, withdrawal rates, rates of absenteeism, levels of anxiety about school, and higher levels of academic performance (Prospero and Vohra-Gupta, 2007). Self-regulation was linked to psychological well-being, while intrinsic motivation was also linked to psychological well-being that was dependent on academic performance (Burton et al., 2006) and higher perceived competence and lower anxiety about course material (Black and Deci, 2000). Studies in Sweden showed IM to be the only motivation type to be associated with positive academic success over a one year period (Taylor et al., 2014).

Gender differences are observed in student motivation, but the evidence seems contradictory. Arrogul, 2009 and Cockley et al., 2001 reported no significant differences between males and females; others indicated that females exhibited higher levels of IM and EM, while males exhibited higher levels of AM (Köseoğlu, 2013, Vallerand, 1992). Yet other studies showed that undergraduate male students exhibited higher levels of EM and IM than females, and females showed higher levels of AM (Hakan and Münire, 2014). In a sample of exercise physiology students in the US, higher levels of IM were related to higher levels of male class performance compared to females (Cortright, 2013). For college in general, females tended to have higher levels of both IM and EM. (Brouse et al., 2010).

The enjoyment of learning was shown to motivate students in some disciplines such as computer science, history, biology, and geology, but not necessarily in others (Breen and Lindsay, 2002). Several studies conducted at our institution used the SDT framework to examine student motivation in nutrition, physics, and human anatomy (HAP) classes (Maurer et al., 2012, 2013). In these three disciplines, both IM and EM were rated higher than amotivation. Differences between majors were observed; nutrition majors exhibited IM, while HAP and physics students exhibited EM (Maurer et al., 2012, 2013). In addition, students who have taken more courses in their chosen major were found to be more intrinsically motivated (Maurer et al., 2013). More recent studies showed that often students are attending college for future rewards, or out of expectation, or obligation. They are most interested in earning a high grade needed for accomplishing a career goal (Labaree, 1997; Pintrich and De Groot, 1990) indicating a more consumerist approach to education. 
Student perceptions of science courses seem to play an important role in academic motivation. A study of nursing students demonstrated that courses deemed to be difficult contributed to low motivation in students (Nilsson and Stomberg, 2008). Other studies indicated that science, technology, engineering, or mathematics (STEM) courses have a high attrition rate in the first two years (Chang et al. 2008), and student performance in introductory courses influences whether they decide to stay with a STEM major (Seymour and Hewitt, 1997).

There are some studies on motivational shifts in chemistry students, but very few which address motivation types in chemistry students. Faculty expectations of students to be motivated to learn chemistry tended to be high at the beginning of the semester (Lammers and Smith, 2008), but student attitudes as measured in a Swedish study shifted toward less motivated behavior over the semester (Berg, 2005). This seems to mirror studies that reported a decline in student motivation over time (Brouse et al., 2011; Hakan and Münire 2014), including students enrolled in chemistry courses (Zusho et al., 2003).

High school chemistry students in Greece exhibited low motivation to learn chemistry (Salta and Koulougliotis, 2015), while organic chemistry students who came to class with self- regulation or who were guided in the process of developing self-regulation, performed better in the course (Black and Deci, 2000).

The emerging field of Discipline Based Education Research (DBER) is changing the approach of educational researchers to the topic of learning in the chemistry classroom. The National Research Council (NRC) cited the DBER report (2012) in which it noted that studies on students' dispositions and motivations towards science and engineering are sparse and that future development of this field of study is important. Our study on student academic motivation in chemistry will add needed data to this growing field.

\section{Research Questions}

The study targeted students at a mid-sized public university in Principles of Chemistry I, since it is the first chemistry course taken by science majors including chemistry, biology, geology, physics, and exercise science. While approximately 50\%, students take the course in their freshman year of college the rest of the students are distributed at the sophomore, junior, and even senior levels (See Table 1). Typical rates of successful completion of the course, as evidenced by a grade of " $\mathrm{C}$ " or higher, are around $75 \%$.

Most students taking the two semester chemistry sequence start in the fall semester and are therefore considered to be on-sequence, while students who take the first course in the spring are considered off-sequence. There are many reasons students might be in an offsequence course. Some have enrolled in the fall, but then withdraw from the course; some have completed it unsuccessfully in the fall; and some have taken time off between semesters for other reasons. Researchers noted a difference in student performance in classes considered off-sequence (Smith et al., 2015). Studies of curricular changes in physics at Colorado University Boulder systematically reported a $3.5 \%$ fall-spring test score difference that was attributed to the differences between on- and off-sequence semesters (Pollock et al., 2007).

The research questions examined in this exploratory study are:

1) Is the adapted AMS a reliable instrument for measuring student motivation in chemistry?

2) What types of motivation do students exhibit in Principles of Chemistry I? 
3) Are motivation types different between males and females and in underrepresented minority (URM) groups?

4) Are there differences in motivation types between on-sequence and off-sequence students?

\section{Methods}

The survey was administered at the beginning of the semester in both Fall 2013 on-sequence and Spring 2014 off-sequence to Principles of Chemistry I students (see Appendix 1). Institutional Review Board (IRB) approval was obtained before conducting the study. No identifying information was collected, and no incentives were given for participation.

\section{Participants}

The participants for the study were 77 undergraduate students enrolled in two sections of Principles of Chemistry I in Fall of 2013, and 234 undergraduate students enrolled in seven sections of Principles of Chemistry I in Spring of 2014. The majority of participants (89\%, $\mathrm{n}=209$ ) noted that the course was required for their major. The demographic distribution of gender, ethnicity, class standing, major, GPA, attendance, time spent studying, and expectations from class are found in Table 1. Allied health majors include exercise science, athletic training, health education and promotion, nutrition and food science students.

\section{Instrumentation}

A non-manipulative, exploratory design with a convenience sample was employed. The participants used the first 15 minutes of class time to complete the paper survey. The 41item survey consisted of 13 demographic questions which included gender, ethnicity, class standing, major (2 items), attendance (2 items), GPA, study habits, and expectations (4 items) along with 28 Likert-scale items adapted from the Academic Motivation Scale (AMS; Vallerand et al., 1992).

The internal consistency is a measure of how well items within a scale describe the same construct (Henson, 2001). Cronbach's alpha $(\alpha)$ is a measure of internal consistency, and literature supports that values greater than 0.70 indicate moderate internal consistency in the measure of classroom rating scales (Murphy and Davidshofer, 2005). The original AMS, constructed of seven subscales, demonstrated the following reliabilities: [AM $(a=.85)$, EMER $(a=.83)$, EM-IN $(a=.84)$, EM-IR $(a=.62)$, IM-ST $(a=.86)$, IM-TA $(a=.85)$, and IMTK $(a=.84)$ ] of four items each (Vallerand et al, 1992). See the Results and Discussion section for the reliabilities of the adapted AMS. 
Table 1: Participant Demographics Fall 2013 and Spring 2014

\begin{tabular}{|c|c|c|}
\hline & $\begin{array}{l}\text { Fall } 2013 \text { Participants } \\
\mathrm{N}=77\end{array}$ & $\begin{array}{l}\text { Spring } 2014 \text { Participants } \\
\mathrm{N}=234\end{array}$ \\
\hline Gender & $\begin{array}{l}\text { Male (42\%), } \\
\text { Female (58\%) }\end{array}$ & $\begin{array}{l}\text { Male (41\%), } \\
\text { Female (59\%) }\end{array}$ \\
\hline Ethnicity & $\begin{array}{l}\text { White (66\%), } \\
\text { African American (22\%), Hispanic (5\%), } \\
\text { Asian (3\%), } \\
\text { Other (3\%) }\end{array}$ & $\begin{array}{l}\text { White (65\%), } \\
\text { African American (29 \%), Hispanic (2\%), } \\
\text { Asian (0.4\%), } \\
\text { Other (1.7\%) }\end{array}$ \\
\hline $\begin{array}{l}\text { Class } \\
\text { Standing }\end{array}$ & $\begin{array}{l}\text { Freshman (57\%), Sophomore (17\%), } \\
\text { Junior (14\%), } \\
\text { Senior }(10 \%)\end{array}$ & $\begin{array}{l}\text { Freshman (50\%), Sophomore (25\%), } \\
\text { Junior (18\%), } \\
\text { Senior (5\%) }\end{array}$ \\
\hline Major & $\begin{array}{l}\text { Biology (22 \%), } \\
\text { Allied Health (40 \%), } \\
\text { Chemistry (20\%), } \\
\text { Engineering (4 \%), } \\
\text { Physics (0\%), } \\
\text { Other (14\%) }\end{array}$ & $\begin{array}{l}\text { Biology (37\%), } \\
\text { Allied Health (30\%), } \\
\text { Chemistry (9\%), Engineering (2.6\%), } \\
\text { Physics (0.9\%), } \\
\text { Nursing (2\%), } \\
\text { Other (19\%) }\end{array}$ \\
\hline $\begin{array}{l}\text { Self-reported } \\
\text { GPA }\end{array}$ & $\begin{array}{l}<2.00(1.3 \%), \\
2.00-2.49(7.8 \%), \\
2.50-2.99(14.3 \%), \\
3.00-3.49(32.5 \%), \\
3.50-4.00(41.6 \%)\end{array}$ & $\begin{array}{l}<2.00(7.3 \%), \\
2.00-2.49(12.4 \%), \\
2.50-2.99(23.6 \%), \\
3.00-3.49(30 \%), \\
3.50-4.00(26.6 \%)\end{array}$ \\
\hline $\begin{array}{l}\text { Frequency of } \\
\text { Attendance }\end{array}$ & $\begin{array}{l}\text { Hardly ever ( } 0 \%) \text {, } \\
\text { Sometimes }(1.3 \%), \\
\text { Most times (6.5\%), } \\
\text { Almost every time (15.6\%), } \\
\text { Every time }(76.6 \%)\end{array}$ & $\begin{array}{l}\text { Hardly ever }(0.4 \%) \text {, } \\
\text { Sometimes }(1.3 \%), \\
\text { Most times }(7.7 \%), \\
\text { Almost every time }(32.5 \%) \text {, } \\
\text { Every time }(58.1 \%)\end{array}$ \\
\hline $\begin{array}{l}\text { Self-Reported } \\
\text { Hours of } \\
\text { Studying per } \\
\text { Week }\end{array}$ & $\begin{array}{l}<1 \text { hour }(10.4 \%), \\
1-3 \text { hours }(48.1 \%), \\
3-6 \text { hours }(32.5 \%), \\
6-9 \text { hours }(7.8 \%), \\
>9 \text { hours }(0 \%)\end{array}$ & $\begin{array}{l}<1 \text { hour }(11.1 \%), \\
1-3 \text { hours }(59.2 \%), \\
3-6 \text { hours }(21.5 \%), \\
6-9 \text { hours }(6.9 \%), \\
>9 \text { hours }(1.3 \%)\end{array}$ \\
\hline $\begin{array}{l}\text { Expectations of } \\
\text { Class Difficulty } \\
\text { in Comparison to } \\
\text { Other Classes }\end{array}$ & $\begin{array}{l}\text { I expect it to be much less difficult ( } 10.4 \%) \text {, } \\
\text { I expect it to be somewhat less difficult } \\
(13.0 \%) \text {, } \\
\text { I expect it to be of the same difficulty } \\
\text { ( } 24.7 \%) \text {, } \\
\text { I expect it to be somewhat more difficult } \\
\text { ( } 36.4 \%) \text {, } \\
\text { I expect it to be much more difficult }(15.6 \%)\end{array}$ & $\begin{array}{l}\text { I expect it to be much less difficult ( } 4.3 \%) \text {, } \\
\text { I expect it to be somewhat less difficult } \\
\text { ( } 15.8 \%) \text {, } \\
\text { I expect it to be of the same difficulty } \\
(22.2 \%) \text {, } \\
\text { I expect it to be somewhat more difficult } \\
\text { ( } 40.2 \%) \text {, } \\
\text { I expect it to be much more difficult }(17.5 \%)\end{array}$ \\
\hline
\end{tabular}

\section{Results and Discussion}

The adapted AMS was tested for reliability for use with undergraduate chemistry students. Predominant motivation types were determined and demographic information was collected. Analyses were conducted on the seven subscales of the AMS to determine adequate reliability for use with the current sample. Additionally, descriptive statistics and frequency of endorsement were used to evaluate the demographic characteristics and motivation trends Journal of the Scholarship of Teaching and Learning, Vol. 18, No. 1, January 2018. 
across the participants. Nonparametric statistics were used to determine the difference between off- sequence and on-sequence students. Finally, ANOVA statistics were used to determine differences in motivation patterns within demographic subgroups of the sample.

\section{Adapted AMS a reliable instrument for measuring student motivation in chemistry}

It was found that the adapted AMS subscales are all highly reliable for use with the current undergraduate chemistry sample. See Table 2 for means and standard deviations. The reliabilities of the subscales for Spring 2014 are as follows: (IM-TK; $a=.93$ ), (IM-TA; $a=$ .86), (IM-ST; $a=.91)$, (EM-ID, $a=.82)$, (EM-IN; $a=.85)$, (EM-ER; $a=.85)$, AM ( $a=$ .84). These results are comparable to results from Fall 2013 reliability analyses [(IM-TK; $a$ $=.93),(\mathrm{IM}-\mathrm{TA} ; a=.86)$, (IM-ST; $a=.92)$, (EM-ID, $a=.80)$, (EM-IN; $a=.87)$, (EM-ER; $a$ $=.85), \operatorname{AM}(a=.82)]$.

Table 2: Psychometric Properties by Semester.

\begin{tabular}{|c|c|c|c|c|}
\hline & $a$ & $M$ & $S D$ & $\begin{array}{c}\text { Ranked Frequency } \\
\text { of Endorsement }\end{array}$ \\
\hline \multicolumn{5}{|c|}{ Fall 2013} \\
\hline IM-TK & .93 & 3.67 & 1.85 & 5 \\
\hline IM-TA & .86 & 3.96 & 1.86 & 4 \\
\hline IM-ST & .92 & 3.26 & 1.60 & 6 \\
\hline EM-ID & .80 & 5.50 & 1.67 & 2 \\
\hline EM-IN & .87 & 4.94 & 1.93 & 3 \\
\hline EM-ER & .85 & 5.70 & 1.86 & 1 \\
\hline $\mathrm{AM}$ & .82 & 1.93 & 1.86 & 7 \\
\hline \multicolumn{5}{|c|}{ Spring 2014} \\
\hline IM-TK & .93 & 3.69 & 1.92 & 5 \\
\hline IM-TA & .86 & 3.97 & 1.96 & 4 \\
\hline IM-ST & .91 & 2.92 & 1.75 & 6 \\
\hline EM-ID & .82 & 4.96 & 1.95 & 3 \\
\hline EM-IN & .85 & 5.51 & 1.78 & 1 \\
\hline EM-ER & .85 & 5.51 & 1.78 & 1 \\
\hline $\mathrm{AM}$ & .84 & 1.93 & 1.51 & 7 \\
\hline
\end{tabular}

\section{Types of motivation exhibited by students in Principles of Chemistry I}

With regard to motivation characteristics across the participants, descriptive statistics revealed that undergraduate chemistry students are largely extrinsic in their academic motivation with 136 participants (58\%) showing the highest endorsement for EM-ER. Only 11 (3.5\%) intrinsic motivation types were found out of all 311 participants. The lowest Journal of the Scholarship of Teaching and Learning, Vol. 18, No. 1, January 2018. 
frequency of endorsement was related to IM-ST with 1 participant (0.4\%). Other categories included IM-TK ( $n=7,2.5 \%)$, IM-TA ( $n=3,1.1 \%)$, EM- ID ( $n=36,12.8 \%)$, EM-IN ( $n=$ $38,13.5 \%)$, and AM ( $n=11,3.9 \%)$. See Table 3. With regard to gender differences across the sample, females $(M=5.05, S D=1.61)$ are significantly more likely to identify with the introjected form of extrinsic motivation (EM-IN) than males $(M=4.28, S D=1.74), F(228)$ $=12.20, p=.001$. Additionally, it was demonstrated that African American students $(M=$ 3.00, $S D=1.70$ ) are significantly more likely to identify with the stimulation form of intrinsic motivation (IM-ST) than White students $(M=2.77, S D=1.40), F(223)=2.78, p=.02$. Shapiro Wilks test demonstrated the normal distribution of data $(\alpha=.32)$.

Several studies were conducted using the SDT framework to examine student motivation, adapted the AMS to specific courses such as nutrition, physics, and human anatomy and physiology (HAP, Maurer, Allen, Gatch, Shankar \& Author, 2012, 2013). In these three disciplines, the AMS proved to have high reliabilities that were consistent with AMS reliabilities in higher education generally (Vallerand et al, 1992), which supports our findings for the adapted AMS for chemistry.

\section{Different types of motivation exhibited between genders and in URM}

Table 3: Important characteristics of motivation in females, males, and URM chemistry students from the Spring 2014 study based on descriptive statistics.

\begin{tabular}{|l|l|l|l|l|l|l|l|}
\hline & \multicolumn{7}{|c|}{ Motivation trends in the Principles of Chemistry Students (Spring 2014) } \\
\cline { 2 - 8 } & \multicolumn{2}{|l|}{ Intrinsic Motivation } & \multicolumn{2}{l|}{ Extrinsic Motivation } & Amotivation \\
\hline $\begin{array}{l}\text { Freq. of } \\
\text { Highest } \\
\text { Endorse- } \\
\text { ment }\end{array}$ & IM-TK & IM-TA & IM-ST & EM-ID & EM-IN & EM-ER & n/ \% \\
\hline Females & 5 & n/\% & n/\% & n/\% & n/\% & \\
\hline Males & 1 & 1 & 0 & 17 & 30 & 76 & 6 \\
\hline URM & $4.68 \%$ & $1.47 \%$ & $0 \%$ & $12.50 \%$ & $22.06 \%$ & $55.88 \%$ & $4.40 \%$ \\
\hline
\end{tabular}

Table 3 offers a descriptive look at frequency of endorsement across gender and URM demographics. As with the overall sample, the data across these categories clearly indicate that the vast majority of students identified most closely with EM-ER, with greater than $50 \%$ of both genders and approximately $46 \%$ of URM rating these items the highest. Additionally, greater than $90 \%$ of females and males rated their own behaviors as aligning with the three types of extrinsic motivation (EM-ER, EM-IN and EM-ID). With regard to URM, over $93 \%$ of students self- reported identification with the aforementioned extrinsic 
motivation types. Conversely, approximately $5 \%$ of females, $4 \%$ of males and $6 \%$ of all URM students reported intrinsic styles of motivation (IM-TK, IM-TA and IM-ST).

While African American students identified more often as IM-Stimulation than their White peers, the overall representation of African Americans in the sample was much lower. Therefore, it is not possible to determine if African American students are more intrinsically motivated or if those students who are intrinsically motivated are attracted to pursuing science majors more frequently than their white peers. There were slight gender differences, with women reporting more intrinsic motivation than men. The results were similar to what was reported in the literature (Salta and Koulougliotis, 2015) as IM was shown to predict academic success for women, while EM-ER tended to be a stronger predictor of success for men (Vecchione et al., 2014).

\section{Differences in motivation types between on-sequence and off-sequence students}

The larger cohort of participants was enrolled in Spring 2014 (234) as compared to Fall 2013 (77). As seen in Table 1, there are some differences in the two groups between self-reported GPA, frequency of attendance, and self-reported hours spent studying. It is possible that these demographic indicators reflect the differences between the on-sequence and offsequence cohorts. ${ }^{6}$ In order to determine the representativeness of the sample with regard to motivation characteristics, a sample of 77 participants from Spring 2014 were randomly selected for comparison to the sample of 77 chemistry students from Fall 2013. Nonparametric tests (Mann- Whitney U) determined that there was no significant difference across the groups in their endorsement of items on any subscale. The nonparametric test was chosen due to the large sample size differences between the Fall 2013 and Spring 2014 participants. The indication that there is no difference in motivation types between onsequence and off-sequence students, contradicts some previous research findings (Smith et al., 2015; Pollock et al., 2007). Whether these differences may be population related or subject related may warrant additional studies.

\section{Implications and Future Directions}

The instrument used in the study was the adapted AMS for chemistry that evaluates academic motivation from within the SDT framework. The adapted AMS had high reliabilities and chemistry instructors at other institutions can use this instrument to determine student motivation types in their own classrooms and potentially adjust instructional practices to improve student learning.

This study added to the paucity of research on academic motivation in college chemistry students (Lammers and Smith, 2008; Berg, 2005) and revealed a predominantly extrinsic motivation type in chemistry classes. These findings support previous research that indicate a shift towards extrinsic motivation (Labaree, 1997; Pintrich and DeGroot, 1990) which seem to span across different subjects and populations. Future research should target chemistry students in advanced chemistry classes, as there seems to be a difference in academic motivation in students who are already taking classes in their major of choice (Maurer et al, 2013).

The findings of this study did not show significant differences in academic motivation between genders, in URM and on-and off-sequence students, adding to the contradictory nature of findings in these populations. Perhaps future studies should target larger samples of these populations (across multiple institutions and/or in longitudinal studies) to elicit differences, if any. In addition, the survey data set was collected at the 
beginning of the semester and did not examine potential changes in motivation over the course of the semester.

Some research in the education domain (Niemiec \& Ryan, 2009; Black and Deci, 2000; Niemiec et al., 2006) indicated that a shift towards more autonomous forms of motivation is possible if instructors provide support for their students' basic psychological needs, such as autonomy, which is the ability to take charge of one's own learning (Holec, 1981). Studies targeting student academic motivation showed that when students experienced autonomous supportive instructors, they demonstrated an increase in autonomous self-regulation, perceived competence, and interest/ enjoyment of the course (Black and Deci, 2000). This can be done by providing choices and meaningful rationales around learning activities to include peer-led supplemental instruction, one on one student interaction, extra office hours, academic success center led programs, and residential peer programs among others. Educators can also act as a mediator by acknowledging students’ feelings and minimizing pressure and control around learning activities (Niemiec \& Ryan, 2009). Given the largely extrinsic types of motivation in chemistry students, as evidenced by this study, instructors may want to consider utilizing teaching practices that can affect the shift towards more successful autonomous motivation.

Our future goal is to use the background data on motivation in chemistry students and incorporate need support training by peer leaders in our classrooms. Both correlational (Niemiec et al., 2006) and experimental (Deci et. al., 1994) studies have shown that autonomous motivation is facilitated by provision of need support (Deci et al, 1999). Strategies that are associated with need support include (1) relating from the student's perspective; (2) encouraging self-initiation and choice; (3) providing a clear rationale for requested behavior; (4) minimizing use of controlling language; (5) being positive that the student can succeed; (6) creating optimal challenges; (7) giving accurate, effectance-relevant feedback; and (8) developing a warm, empathic, non-judgmental relationship with the student (Williams et al., 2011). We plan to provide need support training of peer leaders based on SDT and incorporate peer led sessions into regular class time. This would allow students who are otherwise unable to attend sessions outside regular class time to benefit from peer leaders.

Moreover, the DBER report (2012) pointed out that few studies explore how learning and responses to different instructional strategies vary by student characteristics such as gender, socio- economic status, and ethnicity. Future studies should focus more on the effects of different teaching strategies in different populations.

Research findings are limited by the fact that the data set was collected at one institution in the southeast US. Since the major goal of the study was to examine the motivational types in chemistry students, no identifiable information was included on the survey. As such, we could not study the influence of motivational types on students' academic performance or teacher differences (in use of motivational tools or strategies) on motivation. Future studies could fill these gaps by surveying multiple institutions, linking students' grades to survey responses to examine causality between motivation type and academic performance; by expanding to longitudinal studies to examine whether motivational types change with progression in major or teacher differences, as well as by comparing student motivations as measured by SDT to mindset theory, which describes motivations in the form of mindsets and skills that can be fostered and developed by

\footnotetext{
${ }^{6}$ The initial data set was collected in the Fall and the opportunity to expand the study became available in the Spring, resulting in a larger data set.
} 
educators (Dweck et al., 2014).

\section{Conclusions}

Our results clearly indicate that the adapted AMS is a reliable instrument to measure academic motivation types in chemistry classes. The data set also overwhelmingly supports recent research in that undergraduate students enrolled in chemistry classes at our institution highly endorse external motivation and in particular the least autonomous types. This holds true of both on- sequence and off-sequence students. It could be that the introductory and required nature of this class for many majors, not just chemistry, plays a role in such high endorsement. Future studies with students in more advanced chemistry classes may help determine if student motivation becomes more autonomous as chemistry majors progress in their course of studies. The differences in motivation among genders, as evidenced by our data, may suggest that a differential approach should be used to target males and females in chemistry classes, however future studies on gender differences in the population of chemistry students is warranted. Interventions provided by the instructor, peer leaders, the institution, etc. designed to boost more intrinsic forms of motivation should be encouraged to develop a learning environment conducive to more autonomous types of motivation to facilitate greater student success.

\section{References}

Allen J., Robbins S., Casillas A. and Oh I., (2007), Third-year college retention and transfer: Effects of academic performance, motivation, and social connectedness, Res. High. Educ., 49, 647 - 664. Retrieved from http://dx.doi.org/10.1007/s11162-008-9098-3 on April 5, 2016.

Ariogul S., (2009), Academic motivations of pre-service English teachers, Hacettepe Univeristy J. Educ., 36, 12-19.

Astin A. W., (1984), Student involvement: A developmental theory for higher education, $J$. Coll, Stu. Personnel, 25, 297-308.

Berg C.A.R., (2005), Factors related to observed attitude change toward learning chemistry among university students, Chem. Educ. Res. Pract., 6, $1-18$.

Black A. E. and Deci E. L., (2000), The effects of instructors' autonomy support and students' autonomous motivation on learning organic chemistry: A self-determination theory perspective, Sci. Educ., 84, 740 - 756.

Breen R. and Lindsay R., (2002), Different disciplines require different motivations for student success, Res. High. Educ., 43, 693 - 725.

Brouse C. H., Basch C. E., LeBlanc M., McKinght K. R. and Lei T., (2010), College students' academic motivation: Differences by gender, class, and source of payment, College Quarterly, 13, 1 - 10. Retrieved from http://www.senecacollege.ca/quarterly/2010-vol13num01-winter/brouse-basch-leblanc-mcknight-lei.html on April 5, 2016.

Burton K. D., Lydon J. E., DAlessandro D. U. and Koestner R., (2006), The differential effects of intrinsic and identified motivation on well-being and performance: Prospective, experimental and implicit approaches to self-determination theory, J. Pers. Soc. Psychol. 91, 
$750-762$.

Chang M. J., Cerna O., Han J. and Sáenz V., (2008), The contradictory roles of institutional status in retaining underrepresented minorities in biomedical and behavioral science majors, Rev. High. Ed., 31, 433-464.

Cokley K. O., Bernard N., Cunningham D. and Motoike J., (2001), A psychometric investigation of the academic motivaton scale using a United States sample. Meas. Eval. Couns. Dev., 34, 109 - 119.

Cortright R. N., Lujan H. L., Blumberg A. J., Cox J. H. and DiCarlo S. E., (2013), Higher levels of intrinsic motivation are related to higher levels of class performance for male but not female students, Advan. Physiol. Edu., 37, 227-232. Retrieved from http://advan.physiology.org/content/37/3/227.full-text.pdf+html on April 5, 2016.

Deci E. L., Eghrari H., Patrick B. C. and Leone D. R., (1994), Facilitating internalization: the self-determination theory perspective, J. Pers., 62, 119 - 142. DOI: 10.1111/j.14676494.1994.tb00797.x

Deci E. L., Koestner R. and Ryan R. M., (1999), A meta-analytic review of experiments examining the effects of extrinsic rewards on intrinsic motivation, Psychol. Bull., 125, 692 700. Retrieved from http://content.apa.org/journals/bul/125/6/627 on April 5, 2016.

Deci E. L. and Ryan, R. M., (2008), Self-determination theory: A macrotheory of human motivation, development and health, Can. Psychol., 49, 182-185. DOI: 10.1037/a0012801. Retrieved from http://www.anitacrawley.net/Resources/Articles/Deci\%20and\%20Ryan.pdf on April 5, 2016.

Dweck C. S., Walton, G. M., and Cohen, G. L., (2014), Academic tenacity: mindsets and skills that promote long-term learning, Bill and Melinda Gates Foundation. www.gatesfoundation.org.

Elliot A. J. and Moller A. C., (2003), Performance-approach goals: good or bad forms of regulation?, Int. J. Educ. Res., 39, 339 - 356. DOI:10.1016/j.ijer.2004.06.003

Erten I. H., (2014), Interaction between academic motivation and student teachers' academic achievement, Procedia- Soc. Behav. Sci., 152, 173 - 178. DOI:10.1016/j.sbspro.2014.09.176

Hakan K. and Münire E., (2014), Academic motivation: Gender, domain and grade differences, Procedia- Soc. Behav. Sci., 143, 708 - 715. DOI:10.1016/j.sbspro.2014.07.469

Henson R. K., (2001), Understanding internal consistency reliability estimates: a conceptual primer on coefficient alpha, Meas. Eval. Couns. Develop., 34, 177-189.

Holec H., Autonomy and Foreign Language Learning, (1981), Oxford: Pergamon Press.

Howey S. C., (1999), The relationship between motivation and academic success of community college freshmen orientation students. Doctoral Dissertation. (ERIC Document Reproduction Service No. ED 465391). 
Köseoğlu Y., (2013), Academic motivation of the first-year university students and the selfdetermination theory, Educ. Res. Rev., 8, 418 - 424. Retrieved from http://www.academicjournals.org/journal/ERR/article-full-text-pdf/8DB9FEC5495 on April 5, 2016.

Labaree D. F., How to succeed at school without really learning: the credentials race in American education, (1997), New Haven, CT: Yale University Press.

Lammers W.J. and Smith S. M., (2008), Learning factors in the university classroom: Faculty and student perspectives. Teach. Psychol., 35, 61 - 70.

Maurer T., Allen D., Gatch D. B., Shankar P. and Sturges D., (2012), Students' academic motivations in allied health classes. Internet Journal of Allied Health Sciences and Practice, 10, 1.

Maurer T., Allen D., Gatch D. B., Shankar P. and Sturges, D., (2013), A comparison of students' academic motivations in three courses, Journal of Scholarship of Teaching and Learning, 13, (5), 77-89.

Moore S., Armstrong C. and Pearson, J., (2008), Lecture absenteeism among students in higher education: A valuable route to understanding student motivation, Journal of Higher Education Policy and Management, 30, 15 - 24.

Murphy K. R. and Davidshofer C. O., (2005), Psychological testing: principles and applications, New Jersey: Prentice Hall.

National Research Council, (2012), in Singer, S. R., Nielsen, N. R., and Schweingruber, H. A. (ed.), Discipline-Based Education Research: Understanding and Improving Learning in Undergraduate Science and Engineering, Washington, D.C., National Academies Press.

National Science Foundation, (2012), Science and Engineering Indicators 2012, Arlington, VA (NSF 12-10).

Niemiec C. P., Lynch M. F., Vansteenkiste M., Bernstein J., Deci, E. L. and Ryan R. M., (2006), The antecedents and consequences of autonomous self-regulation for college: a selfdetermination theory perspective on socialization, J. Adolesence, 29, $761-775$. Retrieved from http://selfdeterminationtheory.org/SDT/documents/2006_NiemiecLynchVansteenkisteetal_J OA.pdf on April 6, 2016.

Niemiec C. P., Ryan R. M. and Deci, E. L., (2009), The path taken: Consequences of attaining intrinsic and extrinsic aspirations in post-college life, J. Res. Pers., 43, 291-306. Retrieved from http://www.ncbi.nlm.nih.gov/pmc/articles/PMC2736104/ on April 6, 2016.

Nilsson K. and Stomberg, M., (2008), Nursing students motivation toward their studies- a survey study, Biomed. Central Nursing, 7, 1-7. doi: 10.1186/1472-6955-7-6.

Pintrich P. R., (1988a), A process-oriented view of student motivation and cognition. In J. Stark and L. Mets (Eds.), Improving teaching and learning through research: New directions for institutional research, (Vol. 57, pp. 65-79). 
Pintrich P.R. (1988b). Student learning and college teaching. In R. E. Young and K. E. Eble (Eds), College teaching and learning: Preparing for new commitments. New directions for teaching and learning (Vol. 33, pp. 71-86). SanFrancisco : Jossey-Bass.

Pintrich P. R., (2004), A Conceptual Framework for Assessing Motivation and SelfRegulated Learning in College Students, Educ. Psychol. Rev. 16, 385-407. Retrieved from https://deepblue.lib.umich.edu/bitstream/handle/2027.42/44454/?sequence $=1$ on April 6, 2016.

Pintrich P. R. and DeGroot, E. V., (1990), Motivational and self-regulated learning components of classroom academic performance,J. Educ. Psychol., 82, 33 - 40. Retrieved from http://web.stanford.edu/dept/SUSE/projects/ireport/articles/selfregulation/self- regulated\%20learning-motivation.pdf on April 6, 2016.

Pollock S. J. and Finkelstein N. D., (2012), Impacts of curricular change: Implications from 8 years of data in introductory physics, PERC Proceedings 2012, AIP Press.

Prospero M. and Vohra-Gupta S., (2007), First generation college students: Motivation, integration, and academic achievement. Community College Journal, 31, 963-975.

Ryan R. M., Connell J. P. and Deci E. L., (1985), A motivational analysis of selfdetermination and self-regulation in education. In C. Ames \& R. Ames (Eds.), Research on motivation in education: Vol. 2. The classroom milieu (pp. 13-51). Orlando, FL : Academic Press.

Ryan R. M. and Deci E. L., (2000), Self-determination theory and the facilitation of intrinsic motivation, social development, and well-being, Am. Psychol., 55, 68-78. Retrieved from https://selfdeterminationtheory.org/SDT/documents/2000_RyanDeci_SDT.pdf on April 6, 2016.

Salta K. and Koulougliotis D., (2015), Assessing motivation to learn chemistry: adaptation and validation of science motivation questionnaire II with Greek secondary school students. Chem. Educ. Res. Pract., 16, 237 - 250. doi: 10.1039/C4RP00196F.

Seymour E. and Hewitt N., (1997), Talking about leaving: Why undergraduates leave the sciences. Boulder, CO: Westview Press.

Smith A. F., Guzman-Alvarez A. and Molinaro M., (2015), Understanding the curve: Implications of norm-referenced grading in large introductory science courses, Poster Presented at the Society for Teaching and Learning in Higher Education Conference, Vancouver, BC.

Taylor G., Jungert T., Mageau G. A., Schattke K., Dedic H., Rosenfield S. and Koestner R., (2014), A self-determination theory approach to predicting school achievement over time: the unique role of intrinsic motivation, Contemp. Educ. Psychol., 39, 342-358. Retrieved from http://www.mapageweb.umontreal.ca/mageaug/Articles/Taylor\%20et\%20al\%202014.pdf on April 6, 2016.

Vaino K., Holbrook J. and Rannikmae, Miia., (2012), Stimulating students' intrinsic motivation for learning chemistry through the use of context-based learning modules, Chem. 
Educ. Res. Pract., doi: 10.1039/c2rp20045g.

Vallerand R. J., Pelletier L. G., Blais M. R., Briere N. M., Senecal C. and Vallieres E. F., (1992), The academic motivation scale: A measure of intrinsic, extrinsic, and amotivation in education, Educ. Psychol. Meas., 52, 1003 - 1017. doi: 10.1177/0013164492052004025.

Vansteenkiste M., Lens W., and Deci E. L., (2006), Intrinsic versus extrinsic goal contents in self- determination theory: Another look at the quality of academic motivation, Educ. psychol., 41, 19-31. doi: 10.1207/s15326985ep4101_4.

Vecchione M., Alessandri G., and Marsicano G., (2014), Academic motivation predicts educational attainment: Does gender make a difference? Learn. Individ. Differ., 32, 124131.

Williams G. C., Patrick H., Niemiec C. P., Ryan R. M., Deci E. L. and Lavigne H.M., (2011), The smoker's health project: A self-determination theory intervention to facilitate maintenance of tobacco abstinence, Contemp. Clin. Trials, 32, 535-543. Retrieved from http://www.ncbi.nlm.nih.gov/pmc/articles/PMC3162229/ on April 6, 2016.

Wilson J. H. and Wilson S. B., (2007), The first day of class affects student motivation- An experimental study, Teach. Psychol., 34, 226 - 230. doi: 10.1080/00986280701700151.

Zusho A., Pintrich P.R. and Coppola B., (2003), Skill and Will: The role of motivation and cognition in the learning of college chemistry, Int. J. Sci. Educ., 25, 1081-1094. Retrieved from http://wwwpersonal.umich.edu/ bcoppola/publications/49.\%20Zusho\%20PAPER.pdf on April 6, 2016. 